\title{
Neuroplasticity and motor rehabilitation in multiple sclerosis
}

\author{
Ilona Lipp ${ }^{1,2}$ and Valentina Tomassini ${ }^{1,2,3 *}$ \\ 1 Institute of Psychological Medicine and Clinical Neurosciences, Cardiff University School of Medicine, Cardiff, UK \\ ${ }^{2}$ Cardiff University Brain Research Imaging Centre, School of Psychology, Cardiff University, Cardiff, UK \\ ${ }^{3}$ IRCCS Fondazione Santa Lucia, Rome, Italy \\ ${ }^{*}$ Correspondence: tomassiniv@cardiff.ac.uk \\ Edited by: \\ Maria Assunta Rocca, Vita-Salute San Raffaele University, Italy \\ Reviewed by: \\ Jaume Sastre-Garriga, Centre d'Esclerosi Múltiple de Catalunya, Spain
}

Keywords: brain plasticity, motor recovery, rehabilitation, multiple sclerosis, MRI

\section{INTRODUCTION}

Motor symptoms are common and disabling across the phases and forms of multiple sclerosis (MS). Disease modifying treatments help to prevent their development, but most of their management is through rehabilitation. Current rehabilitation approaches are based on physical therapy tailored to the individual's needs (1). The efficacy of these approaches, however, is limited, as it is purely based on clinical grounds, and is largely unpredictable in the individual case, where several factors, including location, extent, and severity of MS damage, can contribute to individual variation in rehabilitation outcomes (2-7). Therefore, an improved understanding of the neural processes underlying functional recovery and driven by rehabilitation, as well as the development of novel recovery interventions that fully exploit the individual patient's potential to recover motor function remain a clinical necessity and a research priority (8).

\section{NEUROPLASTICITY UNDERPINS RECOVERY OF MOTOR FUNCTION IN MS}

Plasticity is the ability of the nervous system to adapt to the ever-changing conditions of the environment, encountered during development and learning (9-11). Within the central nervous system, such plasticity is sustained by a variety of changes in gray matter (e.g., neurogenesis, synaptogenesis, changes in neuronal morphology), in white matter (e.g., changes in the number of axons, axonal diameter, fiber density, axonal branching and trajectories, myelination), and in other tissue compartments (e.g., glial cell size and number, angiogenesis) (12).

Experimental and clinical studies suggest that brain plasticity also occurs in disease (13), where adaptation to damage contributes to the preservation or to the recovery of function $(14,15)$. In MS, the bulk of evidence suggests that plasticity limits the clinical impact of damage, by establishing patterns of brain activity different from those of healthy volunteers, and accompanies improvements in motor performance with practice, by adaptively reorganizing those altered patterns (6). Indeed, studies on spontaneous recovery after a MS relapse show that changes in activation patterns occur with the resolution of active inflammation (16-18) and parallel recovery of motor function $(16,18)$. Recoveryoriented interventions can also drive these changes further by reorganizing or restoring altered patterns of brain activity (19) and improving behavior even at higher levels of disability and damage (5). Such interventions may also induce clinically meaningful changes in brain structures (20-23), possibly as a result of activity-dependent remyelination.

Not all of the changes in brain activity occurring in MS are adaptive and thus behaviorally beneficial. Evidence suggests that plasticity can also be maladaptive and thus contribute to or sustain disability (24, 25). Indeed, maladaptation may help to explain the functional differences that are observed between clinical stages and forms of MS (26), beyond individual variation in adaptive plasticity and structural reserve. Evidence of maladaptation calls into question, the increase in MS damage as the only factor that limits functional reorganization, as maladaptation itself can contribute to incomplete recovery and progression (27). Probing the limits of plasticity is challenging in MS because of the widespread and multifaceted nature of the disease, with the involvement of both gray and white matter (28), within (29), and outside (30) MS lesions, in the brain as well as in the spinal cord (31). The combination of neurophysiological methods and network-approach to data analysis can offer ways to probe the brain plastic reserve (6) and its behavioral consequences (32). Future interventional studies that interfere with cortical function or studies that assess concurrent structural changes may also disambiguate the relative contributions of inefficient versus insufficient versus ineffectual plasticity (6).

\section{THE EXPLOITATION OF NEUROPLASTICITY PROMOTES AND ENHANCES REHABILITATION-DRIVEN MOTOR RECOVERY}

To promote the individual's potential for recovery in MS by exploiting adaptive plasticity, we need to test novel recovery interventions that combine a strong biological rationale with monitoring of clinically meaningful functional and structural brain reorganization. For these studies, the methodology and neuroscientific rationale need to be carefully considered.

Methodologically, optimized trials that use enriched designs to manipulate behavior through interventions would offer a novel experimental framework for testing efficiently the promotion of adaptive plasticity. Markers of recovery that combine clinical and neurophysiological measures 
could provide insight into the clinically meaningful mechanisms of plasticity and offer a tool for early detection of effects of intervention. Markers predictive of recovery could improve stratification of patients in clinical trials, while developing a personalized approach to recovery-oriented interventions. Technology, especially in the field of neuroimaging [e.g., high field magnetic resonance imaging (MRI)], novel measurements, and sophisticated networklevel analysis $(33,34)$ can now meet this increasing demand for novel markers and predictors. The development of computerbased behavioral measurements also offers sensitive and objective ways to target even subtle deficits and quantify behavioral improvements (35).

Neuroscientifically, an improved knowledge of changes in the brain that accompany functional recovery remains crucial, with the need to distinguish truly adaptive versus maladaptive changes (24), and changes representing compensation versus those representing restitution (36). Additionally, the development of novel strategies for motor recovery requires an improved understanding of the properties of the normal motor system, such as its flexibility and the stability of induced functional and anatomical changes, which vary with development (37) and previous experiences $(38,39)$ and thus inevitably influence the plastic response to damage (13). Approaches that adopt pharmacological and/or non-pharmacological modulation of neuroplasticity to enhance functional recovery represent promising strategies (6). While they pose methodological challenges in terms of prediction of response, qualification of markers of recovery, and development of appropriate outcome measures, these approaches hold promise for clinically meaningful benefits (6) and open therapeutic opportunities for more disabled cohorts (40, 41). Combining experimental evidence with clinical studies will offer a scientifically grounded rationale to develop novel interventions that may predispose (42), promote $(5,19)$, or enhance (6) plasticity underlying functional recovery. In this regard, future therapeutic approaches with novel disease modifying treatments hold promise for combined preventative and neuroprotective (43) or restorative (44) effects that increase further the prospects of and scope for functional recovery.

\section{CONCLUSION}

Rehabilitation of motor function is a major component of MS management that is supported by neuroplasticity, i.e., the brain's ability to adapt to MS damage or disability. Developing novel and more effective rehabilitation approaches, therefore, requires an improved understanding of brain plasticity that can be exploited in recovery interventions. The need for novel rehabilitation approaches, underpinned by promoted and enhanced neuroplasticity, challenges traditional experimental designs. This challenge can be addressed using methodological advances, especially in neuroimaging, which allow improved understanding of mechanisms and detection of intervention effects. In this article, we provide a critical overview of the current knowledge of neuroplasticity and its modulation in MS motor rehabilitation and we offer a vision for future directions of research in this field.

\section{REFERENCES}

1. Beer S, Khan F, Kesselring J. Rehabilitation interventions in multiple sclerosis: an overview. J Neurol (2012) 259(9):1994-2008. doi:10.1007/s00415012-6577-4

2. Langdon DW, Thompson AJ. Multiple sclerosis: a preliminary study of selected variables affecting rehabilitation outcome. Mult Scler (1999) 5(2):94-100. doi:10.1191/135245899678847220

3. Grasso MG, Troisi E, Rizzi F, Morelli D, Paolucci S. Prognostic factors in multidisciplinary rehabilitation treatment in multiple sclerosis: an outcome study. Mult Scler (2005) 11(6):719-24. doi: 10.1191/1352458505ms1226oa

4. Langer-Gould A, Popat RA, Huang SM, Cobb K, Fontoura P, Gould MK. Clinical and demographic predictors of long-term disability in patients with relapsing-remitting multiple sclerosis: a systematic review. Arch Neurol (2006) 63(12):1686-91. doi:10.1001/archneur.63.12.1686

5. Tomassini V, Johansen-Berg H, Leonardi L, Paixao L, Jbabdi S, Palace J. Preservation of motor skill learning in patients with multiple sclerosis. Mult Scler (2010) 17(1):103-15. doi:10.1177/ 1352458510381257

6. Tomassini V, Matthews PM, Thompson AJ, Fuglo D, Geurts JJ, Johansen-Berg H. Neuroplasticity and functional recovery in multiple sclerosis. Nat Rev Neurol (2012) 8(11):635-46. doi:10.1038/ nrneurol.2012.179

7. Kehoe M, Saunders J, Jakeman P, Coote S. Predictors of the physical impact of multiple sclerosis following community-based, exercise trial. Mult Scler (2014). doi:10.1177/1352458514549395

8. Zeller D, Classen J. Plasticity of the motor system in multiple sclerosis. Neuroscience
(2014) 283:222-30. doi:10.1016/j.neuroscience. 2014.05.043

9. Doyon J, Benali H. Reorganization and plasticity in the adult brain during learning of motor skills. Curr Opin Neurobiol (2005) 15(2):161-7. doi:10.1016/j.conb.2005.03.004

10. Giorgio A, Santelli L, Tomassini V, Bosnell R, Smith S, De Stefano N. Age-related changes in grey and white matter structure throughout adulthood. Neuroimage (2010) 51(3):943-51. doi:10.1016/j. neuroimage.2010.03.004

11. Tomassini V, Jbabdi S, Kincses ZT, Bosnell R, Douaud G, Pozzilli C. Structural and functional bases for individual differences in motor learning. Hum Brain Mapp (2011) 32(3):494-508. doi:10. 1002/hbm.21037

12. Zatorre RJ, Fields RD, Johansen-Berg H. Plasticity in gray and white: neuroimaging changes in brain structure during learning. Nat Neurosci (2012) 15(4):528-36. doi:10.1038/nn.3045

13. Nudo RJ. Recovery after brain injury: mechanisms and principles. Front Hum Neurosci (2013) 7:887. doi:10.3389/fnhum.2013.00887

14. Nudo RJ. Adaptive plasticity in motor cortex: implications for rehabilitation after brain injury. $J$ Rehabil Med (2003) 41(Suppl):7-10. doi:10.1080/ 16501960310010070

15. Bosnell RA, Kincses T, Stagg CJ, Tomassini V, Kischka U, Jbabdi S. Motor practice promotes increased activity in brain regions structurally disconnected after subcortical stroke. Neurorehabil Neural Repair (2011) 25(7):607-16. doi:10.1177/ 1545968311405675

16. Reddy H, Narayanan S, Matthews PM, Hoge RD, Pike GB, Duquette P. Relating axonal injury to functional recovery in MS. Neurology (2000) 54(1):236-9. doi:10.1212/WNL.54.5.1175

17. Pantano P, Mainero C, Lenzi D, Caramia F, Iannetti GD, Piattella MC. A longitudinal fMRI study on motor activity in patients with multiple sclerosis. Brain (2005) 128(Pt 9):2146-53. doi:10.1093/ brain/awh549

18. Mezzapesa DM, Rocca MA, Rodegher M, Comi G, Filippi M. Functional cortical changes of the sensorimotor network are associated with clinical recovery in multiple sclerosis. Hum Brain Mapp (2008) 29(5):562-73. doi:10.1002/hbm.20418

19. Tomassini V, Johansen-Berg H, Jbabdi S, Wise RG, Pozzilli C, Palace J. Relating brain damage to brain plasticity in patients with multiple sclerosis. Neurorehabil Neural Repair (2012) 26(6):581-93. doi:10.1177/1545968311433208

20. Ibrahim I, Tintera J, Skoch A, Jiru F, Hlustik P, Martinkova P. Fractional anisotropy and mean diffusivity in the corpus callosum of patients with multiple sclerosis: the effect of physiotherapy. Neuroradiology (2011) 53(11):917-26. doi:10.1007/s00234011-0879-6

21. Bonzano L, Tacchino A, Brichetto G, Roccatagliata L, Dessypris A, Feraco P. Upper limb motor rehabilitation impacts white matter microstructure in multiple sclerosis. Neuroimage (2014) 90:107-16. doi:10.1016/j.neuroimage.2013.12.025

22. Prosperini L, Fanelli F, Petsas N, Sbardella E, Tona F, Raz E. Multiple sclerosis: changes in microarchitecture of white matter tracts after training with a video game balance board. Radiology (2014) 273(2):529-38. doi:10.1148/radiol.14140168 
23. Rasova K, Prochazkova M, Tintera J, Ibrahim I, Zimova D, Stetkarova I. Motor programme activating therapy influences adaptive brain functions in multiple sclerosis: clinical and MRI study. Int J Rehabil Res (2014) 38(1):49-54. doi:10.1097/ MRR.0000000000000090

24. Reddy H, Narayanan S, Woolrich M, Mitsumori T, Lapierre Y, Arnold DL. Functional brain reorganization for hand movement in patients with multiple sclerosis: defining distinct effects of injury and disability. Brain (2002) 125(Pt 12):2646-57. doi:10.1093/brain/awf283

25. Nudo RJ. Plasticity. NeuroRx (2006) 3(4):420-7. doi:10.1016/j.nurx.2006.07.006

26. Rocca MA, Colombo B, Falini A, Ghezzi A, Martinelli V, Scotti G. Cortical adaptation in patients with MS: a cross-sectional functional MRI study of disease phenotypes. Lancet Neurol (2005) 4(10):618-26. doi:10.1016/S1474-4422(05) 70079-X

27. Schoonheim MM, Geurts JJ, Barkhof F. The limits of functional reorganization in multiple sclerosis. Neurology (2010) 74(16):1246-7. doi:10.1212/ WNL.0b013e3181db9957

28. Geurts JJ, Barkhof F. Grey matter pathology in multiple sclerosis. Lancet Neurol (2008) 7 (9):841-51. doi:10.1016/S1474-4422(08)70191-1

29. Tomassini V, Palace J. Multiple sclerosis lesions: insights from imaging techniques. Expert Rev Neurother (2009) 9(9):1341-59. doi:10.1586/ern.09.83

30. Vrenken H, Geurts JJ. Gray and normal-appearing white matter in multiple sclerosis: an MRI perspective. Expert Rev Neurother (2007) 7(3):271-9. doi:10.1586/14737175.7.3.271

31. Rocca MA, Hickman SJ, Bo L, Agosta F, Miller DH, Comi G. Imaging spinal cord damage in multiple sclerosis. J Neuroimaging (2005) 15(4):297-304. doi:10.1177/1051228405280699

32. Barkhof F. The clinico-radiological paradox in multiple sclerosis revisited. Curr Opin $\mathrm{Neu}$ rol (2002) 15(3):239-45. doi:10.1097/00019052200206000-00003
33. He Y, Dagher A, Chen Z, Charil A, Zijdenbos A, Worsley K. Impaired small-world efficiency in structural cortical networks in multiple sclerosis associated with white matter lesion load. Brain (2009) 132(Pt 12):3366-79. doi:10.1093/ brain/awp089

34. Fan AP, Govindarajan ST, Kinkel RP, Madigan NK, Nielsen AS, Benner T. Quantitative oxygen extraction fraction from 7-Tesla MRI phase: reproducibility and application in multiple sclerosis. J Cereb Blood Flow Metab (2015) 35(1):131-9. doi:10.1038/jcbfm.2014.187

35. Prosperini L, Pozzilli C. The clinical relevance of force platform measures in multiple sclerosis: a review. Mult Scler Int (2013) 2013:756564. doi:10.1155/2013/756564

36. Robertson IH, Murre JM. Rehabilitation of brain damage: brain plasticity and principles of guided recovery. Psychol Bull (1999) 125(5):544-75. doi: 10.1037/0033-2909.125.5.544

37. Wandell BA, Smirnakis SM. Plasticity and stability of visual field maps in adult primary visual cortex. Nat Rev Neurosci (2009) 10(12):873-84. doi:10.1038/nrn2741

38. Kim KH, Relkin NR, Lee KM, Hirsch J. Distinct cortical areas associated with native and second languages. Nature (1997) 388(6638):171-4. doi: $10.1038 / 42218$

39. Bengtsson SL, Nagy Z, Skare S, Forsman L, Forssberg $\mathrm{H}$, Ullen F. Extensive piano practicing has regionally specific effects on white matter development. Nat Neurosci (2005) 8(9):1148-50. doi:10. 1038/nn1516

40. Goodman AD, Brown TR, Krupp LB Schapiro RT, Schwid SR, Cohen R. Sustainedrelease oral fampridine in multiple sclerosis: a randomised, double-blind, controlled trial. Lancet (2009) 373(9665):732-8. doi:10.1016/S0140-6736(09)60442-6

41. Braun S, Kleynen M, van Heel T, Kruithof N, Wade D, Beurskens A. The effects of mental practice in neurological rehabilitation; a systematic review and meta-analysis. Front Hum Neurosci (2013) 7:390. doi:10.3389/fnhum.2013.00390

42. Mori F, Kusayanagi H, Buttari F, Centini B, Monteleone F, Nicoletti CG. Early treatment with highdose interferon beta-1a reverses cognitive and cortical plasticity deficits in multiple sclerosis. Funct Neurol (2012) 27(3):163-8.

43. Albrecht P, Bouchachia I, Goebels N, Henke N, Hofstetter HH, Issberner A. Effects of dimethyl fumarate on neuroprotection and immunomodulation. J Neuroinflammation (2012) 9:163. doi:10. 1186/1742-2094-9-163

44. Yong VW. Prospects of repair in multiple sclerosis. J Neurol Sci (2009) 277(Suppl 1):S16-8 doi:10.1016/S0022-510X(09)70006-1

Conflict of Interest Statement: Dr. Ilona Lipp is funded by the MS Society UK. Dr. Valentina Tomassini has received grants for studies on functional recovery in MS from the MS Society UK, MS Society Italy, MS International Federation, Italian Ministry of Health, Merck Serono, Switzerland.

Received: 31 January 2015; accepted: 04 March 2015; published online: 18 March 2015.

Citation: Lipp I and Tomassini V (2015) Neuroplasticity and motor rehabilitation in multiple sclerosis. Front. Neurol. 6:59. doi: 10.3389/fneur.2015.00059

This article was submitted to Multiple Sclerosis and Neuroimmunology, a section of the journal Frontiers in Neurology.

Copyright (c) 2015 Lipp and Tomassini. This is an openaccess article distributed under the terms of the Creative Commons Attribution License (CC BY). The use, distribution or reproduction in other forums is permitted, provided the original author(s) or licensor are credited and that the original publication in this journal is cited, in accordance with accepted academic practice. No use, distribution or reproduction is permitted which does not comply with these terms. 